\title{
Histological Sections of Pancreas and Serum Biochemical Changes in Rats after Dexamethasone and Zinc Oxide Nanoparticles Injection
}

\author{
Ruaa M. Ali ${ }^{1}$, Nada K. Abbas ${ }^{2}$, Amal K. Abbas ${ }^{3}$, Lamia K. Abbas ${ }^{4}$ \\ ${ }^{1}$ Ph.D, / Iraq/University of Baghdad/college of Science for Women/ Physics Dept., ${ }^{2}$ Professor / Iraq/University of \\ Baghdad/College of Science for Women/Physics Dept., ${ }^{3}$ Assistant professor /Iraq/University of Baghdad/College \\ of Science/ Biology dept, ${ }^{4}$ Assistant Professor /Iraq/University of Baghdad/college of Science/ Physics Dept.
}

\begin{abstract}
Zinc Oxide Nanoparticles have been prepared using a simple green synthesis method by green tea extract (Camellia sinensis) as a reducing and capping agent, XRD measurement of Nano powder stated that Zinc Oxide had a hexagonal wurtzite structure, UV-Vis. The maximum absorption peak was approximately 318 $\mathrm{nm}$ and the energy gap was nearly $3.8 \mathrm{eV}$ calculated using Planck's equation, blood serum sugar levels, liver function after $\mathrm{ZnO}$ NPs injection for rats was recorded. Forty-eight adult male rats were used and separated randomly into six groups of eight $(n=8)$ rats in each group.Results stated that blood glucose levels, liver enzymes were increased in groups that injected by dexamethasone while considerably modified in rats administered by the first dose $(100 \mathrm{mg} / \mathrm{kg})$ of ZnO Nanoparticles while the other dose $(300 \mathrm{mg} / \mathrm{kg})$ hadn't any significant effects.
\end{abstract}

Keywords: Dexamethasone, XRD, Zinc Oxide NPS, AST, HDL-C

\section{Introduction}

recently, a strategic development has been frequently implemented in the context of a novel green synthesis technique that forms biocompatible nanoparticles because of the possibility of developing bionanomaterials with particular biological functionalities (1). Today, non-toxic, environmentally friendly techniques have gained more importance because of their ability to generate a wide variety of nanomaterials to cover better suite biomedical applications ${ }^{(2)}$ most of these apps are due to the fact that the Nanometer scale has considerably unique characteristics compared to the bulk. Nanoparticles have good surface bonding, The large surface-volume ratio in nanoparticles is the primary reason for a structural deformation that can influence the physical characteristics of nanoparticles ${ }^{(3)}$ In particular, the synthesis of zinc oxide nanoparticles has gained considerable interest due to the fact that it has excellent characteristics for biomedical apps, zinc ${ }^{(4)}$ plays a significant part in the preservation of blood sugar and activate more than three hundred of body enzymes. (5), it is also known to maintain the structure of insulin and has an important roles in insulin biosynthesis, storage and secretion ${ }^{(6)}$.There are several zinc transporters in pancreatic $\beta$-cells ${ }^{(7)}$. This report intended to investigate the ability of prepared Zinc Oxide by green synthesis to recover blood glucose, liver enzymes and lipids in rat's body after dexamethasone administration.

\section{Materials and Method}

Zinc Acetate Dehydrate $\left(\mathrm{Zn}\left(\mathrm{CH}_{3} \mathrm{COO}\right)_{2} \cdot 2 \mathrm{H}_{2} \mathrm{O}\right)$ $(0.2 \mathrm{M})$ is mixed with $70 \mathrm{ml}$ of Deionized Water using a magnetic stirrer, stirring $1500 \mathrm{rpm}$ a few minutes. Then $20 \mathrm{ml}$ of the previously prepared green tea leaf extract was obtained from the stock solution (stored in the refrigerator) and gradually added. Now the blend was stirred continuously for 2 hours at $40^{\circ} \mathrm{C}$. The solution was then cooled at room temperature and centrifuged twice at $4000 \mathrm{rpm}$ for $15 \mathrm{~min}$ after a thorough washing and then dried at $60^{\circ} \mathrm{C}$ for 3 hours, lastly the produced $\mathrm{ZnO}$ nano-powder pale white colored using for further studies.

\section{Experimental Protocols and Grouping}

(Forty-eight) Male adult Wister albino rats weighing $(175-225 \mathrm{~g})$ and (10-14) weeks old housed in cages 
made of polypropylene under controlled conditions $(25 \pm 5)^{\circ} \mathrm{C}$ and $12 / 12 \mathrm{hrs}$ light / dark cycles, drinking water and diet food were provided ad libitum, animals were grown and housed at the University of Baghdad / animal house in the college of science. The experimental animals were randomly grouped into six groups, each of which consisted of eight rats $(n=8)$ treated for 30 days and designed as follows: G1 the first group was served as negative control, G2 the second group was injected intraperitoneally with $(0.5 \mathrm{mg} / \mathrm{kg})$ dexamethasone sodium phosphate, G3 and G4 were injected intraperitoneally with (100 and 300) $\mathrm{mg} / \mathrm{kg} \mathrm{ZnO} \mathrm{NPs}$ ${ }^{(8)}$ and $(0.5 \mathrm{mg} / \mathrm{kg})$ of dexamethasone respectively, G5 was injected with $100 \mathrm{mg} / \mathrm{kg} \mathrm{ZnO} \mathrm{NPs} \mathrm{and} \mathrm{G6} \mathrm{injected}$ with $300 \mathrm{mg} / \mathrm{kg}$ ZnO NPs. The Laboratory animals were fasted $24 \mathrm{hrs}$ before dexamethasone injection; they were weighed and anesthetized by inhalation in a glass dome.

\section{Biochemical assessment \& Statistical Analysis}

When the experiment period end; blood samples collected from animals by heart puncture, the blood centrifuged at $4000 \mathrm{rpm}$ for $10 \mathrm{~min}$, serum was separated for test of several biochemical parameters such as blood glucose level (BGL) measured by commercially kit (Biosystem, Germany), cholesterol (TC), High Density Lipoprotein Cholesterol (HDL-C), Triglyceride (TG) and Low Density Lipoprotein Cholesterol (LDL-C) estimated using an available kit (Linear kit, Spain), serum levels Alanine Amino transferase (ALT), Aspartate Amina transferase (AST), Alkaline Phosphate (ALP) and Total Bilirubin (TB) were assessed using commercially available kit (Reflotron kit, Germany). Results were stated as means \pm standard Errors. The
Statistical Analysis System applied one way (ANOVA) analysis of variance to verify (LSD) using statistical package of Prism software 8.1.2 (Version 8.1.2, GraphPad, San Diego, CA, USA). The Probability (P) value $\leq 0.05$ has been considered to be of statistical significance. When pancreatic samples collected from animals after organs separation and fixed in $10 \%$ buffered neutral formalin solution, dehydrated in gradual ethanol $(70 \%)$, cleared in xylene, and embedded in paraffin. 5 micron thick paraffin sections were prepared and then regularly stained with Hematoxylin and Eosin (H\&E) ${ }^{(9)}$ and examined microscopically.

\section{Results and Discussion}

Structural characterization of Nano-powder was recorded by Pro Penalty $\mathrm{CAL}$ with $\mathrm{Cu}-\mathrm{K} \alpha$ radiation $(1.5406 \AA)$. X-ray diffraction was indicating the structure and crystalline nature of as synthesized $\mathrm{ZnO}$ Nanoparticles. Results show all diffraction peaks are in good agreement with the international crystallographic data table; JCPDS card No. 01-075-0576. No impurities peaks can associate to the XRD spectrum of the gotten powder, showing high purity of $\mathrm{ZnO}$ products and the peaks intense of the samples proof to good crystallinity. The broadening of the diffraction peaks clearly indicates the presence of Nano-size, large broadening in X-ray diffraction lines occur when particle size is less than $100 \mathrm{~nm}$, The peak width at half height using the Debye-Scherer formula ${ }^{(10)}$ gives indication for average crystallite size of green synthesized ZnO NPs, The calculated average crystallite size was $9.27 \mathrm{~nm}$, result of $\mathrm{X}$ ray pattern agreed with ${ }^{(11)(12)}$.

Table (1): The structural parameters of as synthesized ZnO Nanoparticles

\begin{tabular}{|l|l|l|l|l|l|}
\hline $2 \theta$ (Deg.) & G.S (nm) & FWHM (Deg.) & dhkl Exp. $(\AA)$ & $\begin{array}{l}\text { dhkl standard } \\
(\AA)\end{array}$ & $($ hkl) \\
\hline 30.81 & 14.7 & 0.539 & 2.877 & 2.902 & $(100)$ \\
\hline 34.32 & 8.4 & 0.941 & 2.593 & 2.613 & $(002)$ \\
\hline 35.3 & 9 & 0.883 & 2.523 & 2.537 & $(101)$ \\
\hline 46.7 & 5.33 & 1.497 & 1.943 & 1.941 & $(102)$ \\
\hline 57.97 & 5.54 & 1.470 & 1.592 & 1.595 & $(111)$ \\
\hline 62.15 & 5.25 & 1.516 & 1.492 & 1.493 & $(013)$ \\
\hline 66.93 & 10.3 & 0.773 & 1.396 & 1.398 & $(201)$ \\
\hline 76.5 & 15.7 & 0.510 & 1.243 & 1.268 & $(202)$ \\
\hline
\end{tabular}


The optical behavior recorded by VARIAN spectrophotometer (Cary 5000 Scan), to explain the optical properties and energy gap value of $\mathrm{ZnO}$ NPs; UV-Vis absorption spectrum has been studied. Fig. (1) Shows the exciton maximum absorption is about $318 \mathrm{~nm}$. Actually, energy absorbed in UV or visible region causes a change in the electronic excitation of the molecule, and hence results in corresponding change in its ability to absorb light in the UV-visible region of the electromagnetic radiation. The optical energy band gap for Zno NPs was $3.8 \mathrm{eV}$ has been calculated using Planck's relationship ${ }^{(13)}$.

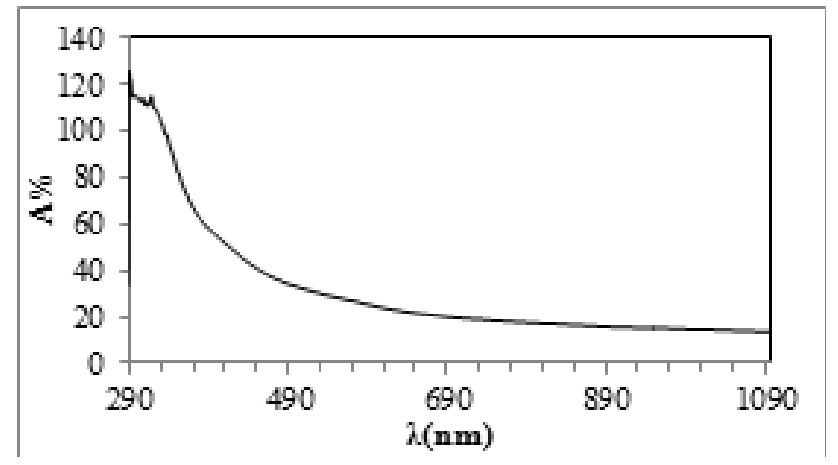

Figure (1): Absorption Spectrum of $\mathrm{ZnO}$ nanoparticles

Table (2) shows blood glucose of the study groups, mean blood glucose level (BGL) of G2 after 30 day administration of dexamethasone showed a significant increasing compared with control group, the reasons behind increasing glucose is generated oxidative stress by sugar causes the generation of free radicals that attack and damage beta cells, thus inhibiting the formation and secretion of insulin, and then stops glucose metabolism and glycogen decomposition, Oxidative stress is involved in creation of ROS that damage cellular membranes, proteins and nucleic acids, the auto oxidation of glucose that produces hydrogen peroxide $\left(\mathrm{H}_{2} \mathrm{O}_{2}\right)$, a strong ROS (14), these results similar to previous study (15) that reported the dexamethasone cause tissue damage in pancreas.

Treatment with $100 \mathrm{mg} / \mathrm{kg}$ of $\mathrm{ZnO}$ NPs were responsible of significant reduction to $\mathrm{BGL}(\mathrm{P} \leq 0.05)$ may be due to that Zinc has been elucidated to be a potent metal that Improves glucose utilization and metabolism through its potent influence on enhancement of hepatic glycogenesis through actions on the insulin signalling pathway ${ }^{(16)}$, interestingly, on the basis of Umrani and Paknikar ${ }^{(17)}$; $\mathrm{ZnO}$ did not possess the risk of hypoglycemia in living organisms so it can act as an insulin secretion, more researches have the same results revealed that $\mathrm{ZnO}$ NPs could increase serum insulin level in diabetic animals ${ }^{(18)}$.

Table (2): Changes of Serum biochemical parameters in treated rats with $\mathrm{CeO}_{2}$ Nanoparticles after 30 days, Each value represents the mean \pm standard error of $(n=8)$, The values were found to be statistically significant at $\mathbf{P} \leq 0.05,\left({ }^{*} \mathbf{P}<0.01, * * \mathrm{P}<0.001, * * * \mathrm{P}<0.0008, * * * * \mathrm{P}<0.0001\right)$

\begin{tabular}{|l|l|l|l|l|l|l|}
\hline \multicolumn{7}{|l|}{ Means \pm SE } \\
\hline $\begin{array}{l}\text { Groups } \\
\text { Parameters }\end{array}$ & G1 & G2 & G3 & G4 & G5 & G6 \\
\hline BGL (mg/dL) & $113.2 \pm 6.4$ & $395.2 \pm 29.7$ & $130.2 \pm 18.9^{* *}$ & $236.7 \pm 5.1^{*}$ & $110.25 \pm 0.8$ & $121.25 \pm 6.4$ \\
\hline ALT(IU/L) & $35.7 \pm 1.6$ & $66.2 \pm 4.7$ & $33.7 \pm 1.6^{*}$ & $46.5 \pm 0.6$ & $41.2 \pm 0.6$ & $43.7 \pm 1.6^{*}$ \\
\hline AST(IU/L) & $27.2 \pm 4.4$ & $48.2 \pm 3.5$ & $34.5 \pm 2.3^{*}$ & $58 \pm 3$ & $31 \pm 1.6$ & $38.2 \pm 1.2$ \\
\hline ALP(IU/L) & $151 \pm 17.8$ & $383.2 \pm 30.7$ & $124 \pm 7.5^{* *}$ & $317.5 \pm 8.5$ & $159.5 \pm 12.7$ & $238.2 \pm 20.5^{*}$ \\
\hline TB(mg/dL) & $0.33 \pm 0.01$ & $1.42 \pm 0.08$ & $0.54 \pm 0.02^{* *}$ & $1.27 \pm 0.04$ & $0.45 \pm 0.06$ & $0.62 \pm 0.1$ \\
\hline TC(mg/dL) & $178.5 \pm 12.5$ & $255 \pm 5.4$ & $139.7 \pm 13.8^{* *}$ & $232.7 \pm 5.9^{*}$ & $164 \pm 4.2$ & $173.2 \pm 5.5$ \\
\hline TG(mg/dL) & $152.2 \pm 10$ & $231.7 \pm 14.8$ & $170.5 \pm 2.2^{*}$ & $203.7 \pm 3.8$ & $157 \pm 1.9$ & $165.7 \pm 2.9$ \\
\hline HDL-C(mg/dL) & $45 \pm 1.6$ & $26 \pm 3$ & $46.2 \pm 2.3^{*}$ & $29 \pm 1.4$ & $40.2 \pm 2.2$ & $35 \pm 1.7$ \\
\hline LDL-C(mg/dL) & $91.2 \pm 8.1$ & $172 \pm 13.1$ & $115.2 \pm 3.9^{*}$ & $163.5 \pm 5.1$ & $101.7 \pm 2.4$ & $113.7 \pm 2.4$ \\
\hline
\end{tabular}


ALT and AST are very sensitive enzymes and have been closely connected with hepatic damage these levels enzymes will rise when liver is in dysfunction (19) (20), Maiti et al. (21) have suggested that increases in the actions of ALT, AST, and ALP in the serum of diabetic rats as a consequence of hepatic damage, ALT and AST levels increased is associated with insulin deficiency has been interrelated to increased gluconeogenesis during hyperglycemia ${ }^{(22)}$.

The results showed there was a significant increase in liver functions parameters such as ALT, AST and ALP in experimental animals compared with negative control group (G1) table (2), increases of liver functions parameters levels possibly due to hepatic damage and increase synthesis of these enzymes in the liver ${ }^{(23)}$, and a significant decrease $(\mathrm{P} \leq 0.05)$ with liver enzymes when animals treated with $(100 \mathrm{mg} / \mathrm{kg})$ of $\mathrm{ZnO}$ NPs while there was no statistically significant effect of $300 \mathrm{mg} /$ $\mathrm{kg}$ dose for infected rats respect to G2. Increases of Bilirubin levels may be attributed to the changes in cell membrane permeability with change of effective stress of the membrane under the oxidative stress ${ }^{(24)}, \mathrm{ZnO}$ nanoparticles have reduced Bilirubin levels in G3; G5 and G6 were nearly the normal ranges.

G2 had a significant increase in cholesterol; this increasing attributed to high exposure of free radicals which stimulate the rate limiting enzyme hydroxylmethyl glutaryl which is responsible for liver synthesis (25). When these animals treated with $100 \mathrm{mg} / \mathrm{kg}$ of $\mathrm{ZnO}$ NPs, a significant recovery in cholesterol levels occurred. Higher levels of Triglycerides (TG), LDL-C and reduction in HDL-C levels in $\mathbf{G 2}$ is possibly due to a direct consequences of conversion white adipocytes to brown adipocytes ${ }^{(26)}$, or may be attributed to decrease the activity of lipoprotein lipase which is responsible for TG removal. However, triglyceride and LDL-C levels $(P \leq 0.05)$ decreased was evident. With the exception of raises of serum HDL level.

Histological section in (Fig. 2a) shows pancreatic lobules containing acini $(*)$, islets of Langerhans $(* *)$ and unstained connective tissue septa $(* * *)$ for control group. Fig. ( $2 b$ and $c)$ showed damage and necrosis of endocrine cells of islet $(*)$, Langerhans with shrinkage of islet (**), degenerated acini cells and islet of Langerhans $(* * *)$ and presented different alterations of rat's pancreas and many histological changes were detected in pancreas section of (G2) that administrated by dexamethasone, such as necrosis and damage of endocrine cells of islet Langerhans with shrinkage of islets, Dexamethasone induced necrosis is mediated by reactive oxygen species mediated lipid peroxidation which causes bursting of plasma membrane of the cell and disturbance of osmotic balance this osmotic alteration ultimately leads the cell towards necrosis. The histological sections showed several modified in rats pancreas of rats in groups that treated with $50 \mathrm{mg} / \mathrm{kg}$ of $\mathrm{ZnO}$ Nanoparticles (G3), whereas group that treated with $(100 \mathrm{mg} / \mathrm{kg})(\mathbf{G} 4)$ had no clear changes after dexamethasone and nanoparticles injection, in fig. (3a) the section shows animal from G3 had a normal histological structure of islets of Langerhans of pancreas which consist of $\alpha$ and $\beta$ cells, in between capillaries blood vessels, while fig. (3b) section shows no effects of Nanoparticles on pancreatic cells, abundant necrosis, degenerated acini and damage of endocrine cells, G5 and G6 in fig. (3c and d) appears look like normal pancreatic structure.

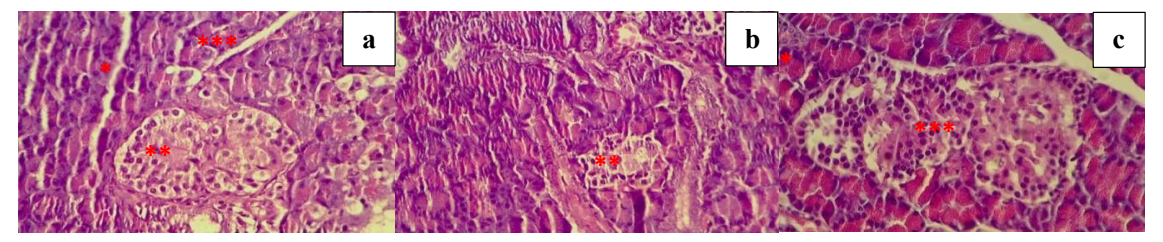

Figure (2): Cross sections of pancreas (a) Control group G1, (b and c) G2 X400 (H\&E)

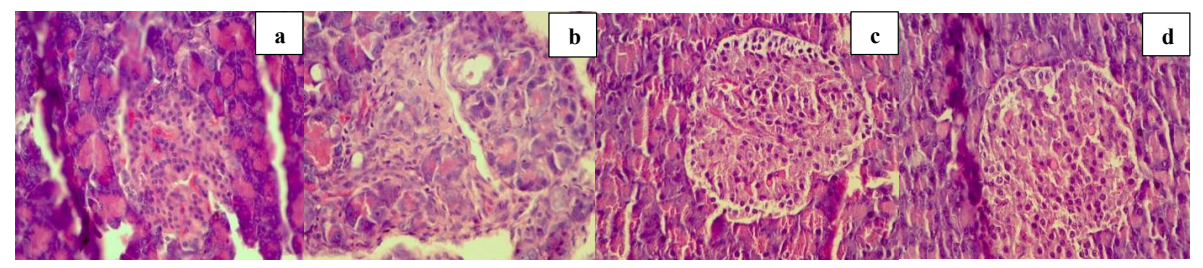

Figure (3): Cross section of pancreas (a) G3 (b) G4 (a) G5 (b) G6 X400 (H\&E). 


\section{Conclusions}

Biocompatible nanoparticle synthesis was produced by using green tea extract (Camellia Sinensis) method for the preparation of Zinc Oxide nanoparticles. Successful formation of nanoparticles by examining its structural and optical properties was investigated. Results indicated that blood glucose concentrations, liver enzymes and lipids were enhanced in dexamethasone-injected groups, while significantly altered in rats administered $100 \mathrm{mg}$ / $\mathrm{kg}$ dose of ZnO NPs and the other dose (300 mg / kg) did not significantly improve BGL, liver enzymes and lipids.

Ethical Clearance: The Research Ethical Committee at scientific research by ethical approval of both environmental and health and higher education and scientific research ministries in Iraq

Conflict of Interest: The authors declare that they have no conflict of interest.

Funding: Self-funding

\section{References}

1. Prasad K., Jha A.K, ZnO Nanoparticles: Synthesis and adsorption study, Nat Sci. 2009;1, 129-135.

2. Nagajyothi P.C., Minh An T.N., Sreekanth T.V.M., Lee Jae-il, Dong Joo Lee, Lee K.D., Green route biosynthesis: Characterization and catalytic activity of $\mathrm{ZnO}$ nanoparticles, Materials Letters. 2013;108, $160-163$.

3. Nada K. A., Anwar A. B., Nadia J. G. The effect of annealing temperature on the optical properties of (Cu2S) 100-X (SnS2)X thin films. Baghdad Science Journal. 2014; 11(2).

4. Chausmer, A. B.. Zinc, insulin and diabetes J. Am. Coll. Nutr. 1998;17(2): 109-115.

5. Haase, H., Overbeck, S., Rink, L.. Zinc supplementation for the treatment or prevention of disease: current status and future perspectives. Exp. Gerontol. 2008;43(5): 394-408 .

6. Sun, Q., VanDam, R.M., Willett, W.C., Hu, F.B.. Prospective study of zinc intake and risk of Type 2 diabetes in women. Diabetes Care. 2009;32(4), 629-634.

7. Smidt, K., Jessen, N., Petersen, A.B., Larsen, A., Magnusson, N., Jeppesen, J.B., Stoltenberg, M., Culvenor, J.G., Tsatsanis, A., Brock, B.. SLC30A3 responds to glucose- and zinc variations in b-cells and is critical for insulin production and in vivo glucose-metabolism during b-cell stress. 2009;PLoS ONE4 (5):e5684-e5691.

8. Mansouri E., Khorsandi L., Orazizadeh M., Jozi Z., and Sciences M., Dose-dependent hepatotoxicity effects of Zinc oxide nanoparticles. 2015;vol. 2, no. 4, pp. 273-282,

9. Bancroft J.D., Gamble M., Theory and Practice of Histological Technique, 2008; 4th Ed.; Churchill: Livingston, NY, USA.

10. Sitrotin Y. and Shaskolskaya M., Fundamental of crystal physics", Mir publishers, Moscow, (1983).

11. Suresh J., Pradheesh G., and Alexramani V., Green synthesis and characterization of zinc oxide nanoparticle using insulin plant (Costus pictus D. Don) and investigation of its antimicrobial as well as anticancer activities, Adv. Nat. Sci.:Nanosci. Nanotechnol. 2018;9, 015008-8.

12. Senthilkumar S. R. and Sivakumar T., Green tea (Camellia sinensis) mediated synthesis of zinc oxide $(\mathrm{ZnO})$ nanoparticles and studies on their antimicrobial activities, Int $J$ Pharm Pharm Sci, 2014; 6(6), 461-465.

13. Alkauskas A., Pasquarello A., Band-edge problem in the theoretical determination of defect energy levels: The $\mathrm{O}$ vacancy in $\mathrm{ZnO}$ as a benchmark case, 2011; J. Phys. Rev. B. 84-125206.

14. Wolff, S.P., Dean, R.T., Glucose autoxidation and protein modification. The potential role of autoxidative glycosylation in diabetes" Biochem. J. 1987;245, 243-250.

15. Karmakar R., Chatak S., Haidar A., Bhaltacharya S. Predenisolone-induced alteration in hepatic and muscular protein and glycogen level. Its correlation with blood glucose level in mice. Folia Biol. Prague. 1998;44(6):217-225.

16. Jansen, J.; Karges, W.; Rink, L. Zinc and diabetesClinical links and molecular mechanisms.J. Nutr. Biochem. 2009, 20, 399-417.

17. Umrani, D.R.; Paknikar, K.M. Zinc oxide nanoparticles show antidiabetic activity in streptozotocin-induced Types 1 and 2 diabetic rats. Nanomedicine 2014, 9, 89-104.

18. Ali Alkaladi, Aaser Mohamed Abdelazim 'Antidiabetic Activity of Zinc Oxide and Silver Nanoparticles on Streptozotocin-Induced Diabetic Rats Int. J. Mol. Sci. 2014, 15, 2015-2023; doi: 10.3390/ijms15022015. 
19. Spano, J. S., August, J. R., Henderson, R. A., Dumas, M. B. and Groth, A. H. "Serum gamma-glutamyl trans-peptidase activity in healthy cats and cats with induced hepatic disease", American Journal of Veterinary Research, 44(11): 2049 -2053(1983).

20. Dkhil MA, Al-Quraishy S, Diab MM, Othman MS, Aref AM, Abdel Moneim AE. The potential protective role of Physalis peruviana L. fruit in cadmium-induced hepatotoxicity and nephrotoxicity. Food Chem Toxicol. 2014; 74:98106.

21. Maiti S, Ali KM, Jana K, Chatterjee K, De D, Ghosh D. Ameliorating effect of mother tincture of Syzygium jambolanum on carbohydrate and lipid metabolic disorders in streptozotocin-induced diabetic rat: Homeopathic remedy. J Nat Sci Biol Med. 2013;4(1):68-73.

22. Nabi SA, Kasetti RB, Sirasanagandla S, Tilak TK, Kumar MV, Rao CA. Antidiabetic and antihyperlipidemic activity of Piper longum root aqueous extract in STZ induced diabetic rats. BMC Complement Altern Med. 2013;13:37.

23. Hadi N. R., Al-Amran F.G., Swadi A. Metformin ameliorates methotrexate- induced hepatotoxicity. J.Pharmacol Exp. Ther. 2012;3(3):248-253.

24. Cassim L. melatonin and anticancer therapy: interaction with 5-fluorouracil. $\mathrm{PhD}$ thesis, Rhodes university, pp.225, 2007.

25. Abdul- Barry J. A., Al-Naama L. M. serum malondialdehyde, total cholesterol, high density lipoprotein and vitamin $\mathrm{c}$ in welder workers. Med. J. Babylon. 2009;6(2):370-376.

26. Hesselbarth N., Pettinelli C., Gericke M., Berger C., Kunath A. Tamoxifen affects glucose and lipid metabolism parameters, causes browning of subcutaneous adipose tissue and transient body composition changes in C57BL/6NTac mice. Bioch. Biophys. Res.Commun. 2015;464(3):724-729. 